\title{
XLIV. On the susceptibility of diamagnetic and weakly magnetic substances
}

\section{Albert P. Wills}

To cite this article: Albert P. Wills (1898) XLIV. On the susceptibility of diamagnetic and weakly magnetic substances, Philosophical Magazine Series 5, 45:276, 432-447, DOI: 10.1080/14786449808621149

To link to this article: http://dx.doi.org/10.1080/14786449808621149

册 Published online: 08 May 2009.

Submit your article to this journal ¿

Џ Article views: 2

Q View related articles $\sqsubset$ 
$\$ 84$. Experiments were made to make sure that the result. was not due to temporary electrification of the glass. For instance I breathed on the glass, causing a conducting layer of impure water to form on its surface. Repeated measurements, made by the usual method, showed that the potential at once fell to a small fraction of a volt, but slowly rose again to nearly its original value as the film evaporated. This shows that the electrification was not a temporary one of the glass surface, for that would not have returned to a definite value. Heating the plate by radiation or washing the glass with benzol caused the potential 10 rise further, but in no case was the potential quite so high as when the plate was first formed. An even more convincing proof that the potential mensured was really that of the sodium was found in the fact that the sensibility of the apparatus was such as would be given by a plate the size of the sodium. If the electritication had been on the whole surface of the glass, the sensibility, on account of the larger surface, would have been at least ten times as great as that obsorved.

$\$ 85$. The experiments described in this chapter show that (i.) when two metals are coated with the same non-conductor, such as wax or glass, their potential is not sensibly different from that of the bare metals in air ; (ii.) that temperaturevariation still takes place, though air be excluded. 'These results seem to prove that gaseous films play no essential part in the phenomenon.

XLIV. On the Susceptilility of Diamagnetic and Weakly Magnetic Substances. By Albert P. Wills*.

FARADAY (1845) showed that all substances, whether solid, liquid, or gaseous, are either diamagnetic or magnetic. Previously, however, Brugmans (1778) and Becquerel (1827) observed certain diamagnetic phenomena.

$\mathrm{By}$ way of relative measurement of the coefficient of susceptibility, a great deal has been done by various physicists, among them Plücker and Faraday. For bismuth there have been a number of determinations in absolute measure. It will suffice to mention here four of the best methods used : -1 . The method used by Christiet (1858) depends upon the comparison of the inductive action of the magnetized bismuth with that of a solenoid through which a known current is flowing. 2. The method used by Töpler

* Communicated by Prof. A. G. Webster.

$\dagger$ Porg. Ann. ciii. p. 577 (1858). 
Diamagnetic and Weakly Magnetic Substances.

and von Ettingshausen* (1877) depends upon the measurement of the force of repulsion upon a piece of bismuth hung near the end of a solenoid. 3. The method used by Rowland and Jacques $\dagger$ (1879) depends upon the measurement of the influence of the diamagnetic force upon the time of swing of a piece of bismuth suspended in an inhomogeneous magnetic field. 4. The method used by von Ettingrbausen $\$$ (1852) depends upon the mastrement directly of diamagnetic action at a distance.

von Ettingshausen has used all the above-mentioned methods, and for an interesting comparison of results obtained with these methods, a takle, taken from Winkelmann's IIandbuch der Physik, is suljoined:-

$$
\begin{aligned}
& \text { Values of } \kappa \text { for Bismuth. } \\
& \text { Obzerver. } \quad \text { Extreme Values. Mean Values. } \\
& \text { v. Ettingshauseu } 1 \text { Method } \ldots 1335 \text { to } 13.82 \times 10^{-6} \quad 1357 \times 10^{-6}
\end{aligned}
$$

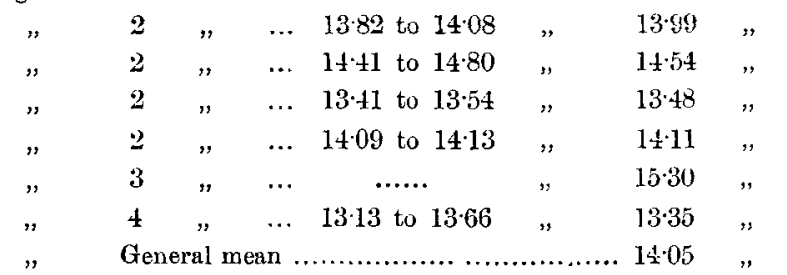

von Ettingshausen also made absolute determinations of the susceptibility for antimony and tellurium. There has been a considerable amount of work done by various physicists by way of determination of the susceptibility for liquids and gases. A great number of liquids and gases have been used, and the susceptibility has been determined for them by different methods. The results thus obtained sometimes differ widely.

Concerning the determination of the susceptibility for bodies in which it is exceedingly small it may be said that the methods previously used have sometimes suffered greatly in consequence of the weakness of the action to be observed. No doubt many of the divergent results obtained by different physicists are due in large measure to dissimilarity in the samples of the substance experimented upon. In some cases, however, they seem due to some chronic weakness in the method of experimentation. A fundamental difficulty met with in the elaboration of a method for the study of diamag-

* Pogg. Ann. clx. p. 1 (1877).

+ Amer. Journ. Sci. xviii. p. 360 (1879).

† Wien. Ber. Ixxxv. [2] p. 37 ; Wied. Anu. xrii. p. 272 . 
netic phenomena lies in making the inevitably small action as large as possible.

In the autumn of $1895^{*}$, acting upon the suggestion of Prof. A. G. Wehster, I attempted to determine the susceptibility of substances by suspending an ellipsoid of the substance in a homogeneous magnetic field, and observing the times of oscillation with a known field and with no field. I failed in this object owing to the fact that I was unable to obtain a field. which was uniform to a sufficient degree of approximation, the effect which I wished to observe depending upon the square of the extremely small quantity $\kappa$, while the effect depending upon the non-uniformity of the field varies with the first power of $\kappa$.

The purpose of the present paper is to describe a method for the determination of $\kappa$ for bodies in which it is extremely small and either positive or negative, and to give the actual results obtained from experiments upon a large number of substances.

\section{Description of the Apparatus.}

It has long been known that if any substance be introduced into an inhomogeneous magnetic field it experiences a mechanical force which tends to make it enter a stronger or weaker part of the field, according as the substance is magnetic or diamagnetic. To determine this force the amount and distribution of the field in which the substance is placed must be known.

I shall describe the apparatus used in the present experiments, and in the theory of the method shall show that the apparatus as here described is adequate to allow for certain simplifications in the general theory, giving the force acting on a body placed in an inhomogeneous magnetic field. As a result of these simplifications we get an expression for the mechanical force upon the body in a convenient direction, which involves the field-strength at the two limiting surfaces only, in that direction. A suitable form for the experimental body is that of a thin rectangular slab. Fig. 1 will give a general idea of the arrangement of the apparatus.

* In connexion with this work I noticed a very remarkable behaviour of non-conductors in a magnetic field, which led me to suspect an action akin to hysteresis in iron. As my direct olject at that time was to establish a method for the determination of cuefficients of susceptibility I did not push my experiments far enough to warrant my publishing results. Mr. Duane has published (Wied. Ann. Bd. lviii. p. 517, 1896) an account of similar experiments performed by him in the physical laboratory at Berlin, which seemed to indicate hysteresis in non-conductors, but in which later research showed the effect to be due to traces of iron (Wied. Ann. lxi. p. 436, 1897). 
Fig. 1.

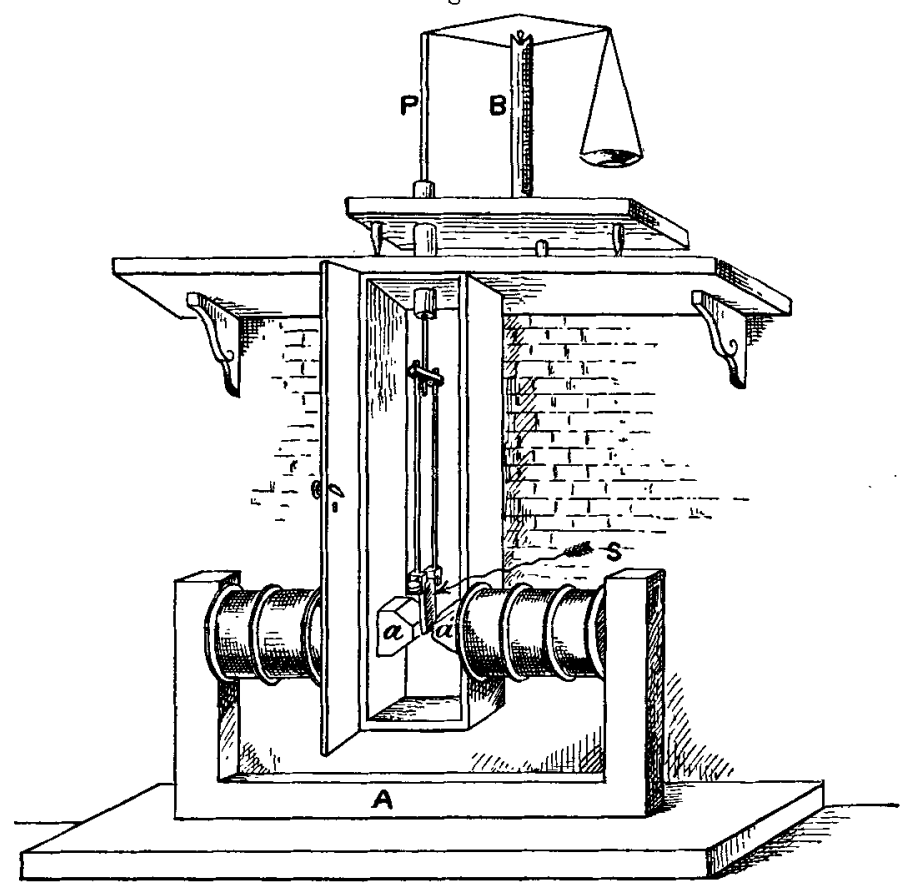

A. Large electromagnet.

$a, a^{t}$. Pole-pieces of A

S. Experimental slab in position.

B. Balance.

The pole-pieces are prismatic, as shown in figs. 2 and 3 . Fig. 2.

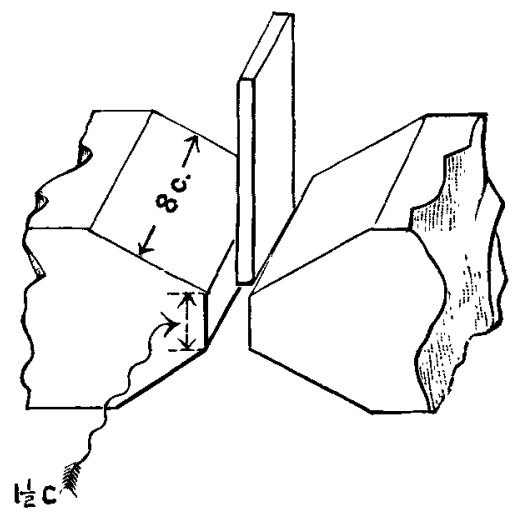


Fig. 3.

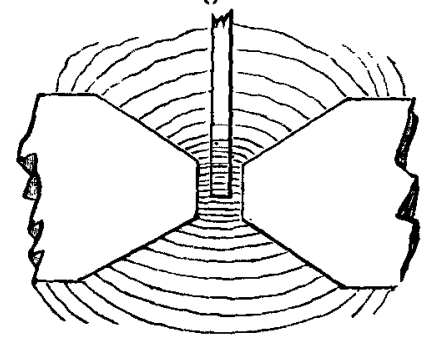

The bevelled faces are on angles of 60 degrees. When in position the pole faces are parallel, and the gap between them is about 1.5 centim. The figures given on the diagram represent centimetres.

Fig. 4.

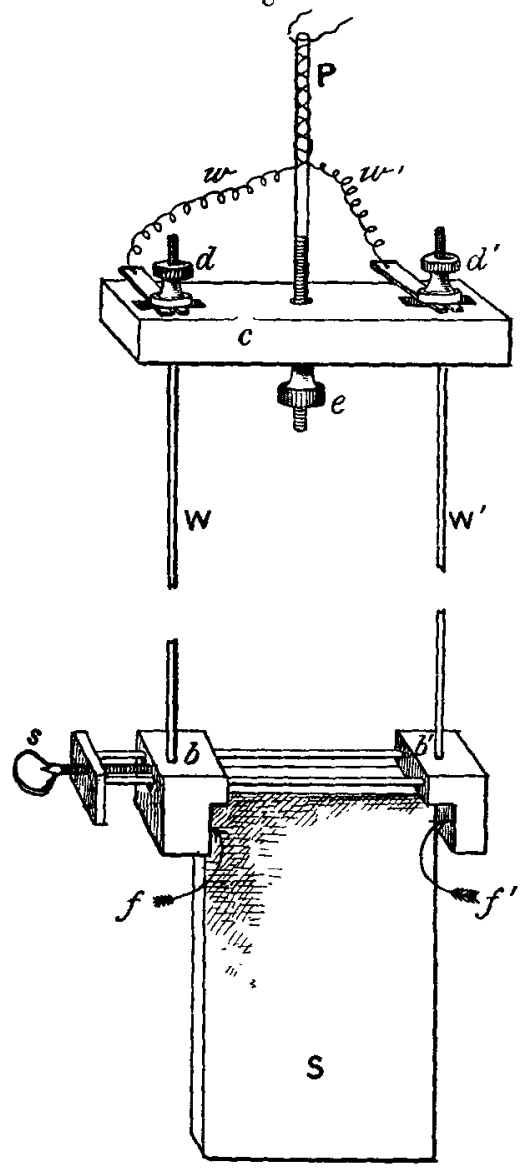


In fig. 4 is shown the suspension arrangement used in holding the slab. $\mathrm{P}$ is the suspension-wire from the balance beam passing through the vulcanite cross-arm $c . W^{2}$ and $W^{\prime}$ are rigid brass wires passing easily through slots in $c$, and supported by means of nuts $d$ and $d^{\prime}$, the upper ends of $\mathrm{W}$ and $W^{\prime}$ being threaded ; $b$ and $b^{\prime}$ are small vulcanite blocks to which the rigid wires $\mathrm{W}$ and $\mathrm{W}^{\prime}$ are firmly attached. $\mathrm{A}$ part of the surface $f$ of block $b$ is made conducting and in metallic connexion with $\mathrm{W}$; likewise a conducting part of surface $f^{\prime}$ is in metallic connexion with $W^{\prime}$. For holding the slab $\mathrm{S}$, a clamp operated by the serew $s$ is used ; for making the necessary adjustments in the positions of $\mathrm{S}$, the nuts $e, d, d^{\prime}$ serve. The reason for making the surfaces $f$ and $f^{\prime}$ partly conducting and in metallic connexion with $W$ and $W^{\prime}$ respectively will be made clear when the method used in making the field determination is described. In cirenit with the magnet coils of $A$ there is an ammeter which, with a variable resistance, serves to keep the current constant during an experiment. In the same circuit there is also a commutator which serves to change readily the direction of the current through the magnet coils.

A box, opened in front by means of a door, serves to protect the suspension apparatus from draughts.

An idea of the general distribution of the field is given in fig. 3 .

The slabs used in the experiments were rectangular in shape and of approximate dimensions 8 centim. by 4.5 centim. by 0.5 centim. When in position for experimenting the long edges of the slab were vertical. Figs. 1, 2, and 3 show more clearly than could any description how the slabs were suspended.

\section{Theory of the Method.}

Considering magnetic forces due to stresses in the media, it can then be shown ${ }^{*}$ that the following equations must in general be satisfied for isotropic media :-

$$
\begin{aligned}
\mathrm{X} & =\frac{1}{8 \pi}\{2 \mathscr{L} \mathrm{L}-\mathfrak{B H}\}, \\
\mathrm{Y}_{y} & =\frac{1}{8 \pi}\{2 \mathfrak{N} \mathrm{N}-\mathfrak{B H}\}, \\
\mathrm{Z}_{z} & =\frac{1}{8 \pi}\{2 \mathfrak{N N}-\mathfrak{B H}\},
\end{aligned}
$$

* See, for instance, Webster, 'Electricity and Magnetism,' p 387. 


$$
\begin{aligned}
& \mathrm{Y}_{z}=\mathrm{Z}_{y}=\frac{1}{4 \pi} \mathfrak{l N}=\frac{1}{4 \pi} \mathfrak{R M}, \\
& \mathrm{Z}_{x}=\mathrm{X}_{z}=\frac{1}{4 \pi} \mathfrak{N L}=\frac{1}{4 \pi} \mathfrak{l N}, \\
& \mathrm{X}_{y}=\mathrm{Y}_{x}=\frac{1}{4 \pi} \mathfrak{l M}=\frac{1}{4 \pi} \mathfrak{N L} .
\end{aligned}
$$

where $\mathrm{X}_{x}$ represents the $\mathrm{X}$-component of the force per unit of area upon a plane element perpendicular to the $\mathrm{X}$-axis (an analogous meaning is to he given $\mathrm{Y}_{y}, \mathrm{Z}_{z}$, and $\mathrm{X}_{y}, \mathrm{X}_{z}, \mathrm{Y}_{x}, \mathrm{Y}_{z}$, $\left.Z_{x}, Z_{y}\right)$, and $L, M, N, \mathfrak{L}, \mathfrak{W}$, $\mathfrak{R}$ are the components of the magnetic force $\mathrm{H}$ and the magnetic induction $\mathfrak{B}$ respectively.

Referring to fig. 3, let the axis of $\mathrm{X}$ be in the line of symmetry perpendienlar to the pole faces; let the axis of $\mathrm{Z}$ be vertical and the axis of $Y$ be perpendicular to the axes of $X$ and $Z$. We wish to find an expression for the mechanical force acting upon the slab when placed relatively to the polepieces as shown in fig. 3. There will be discontinuity in the stress-components $\mathrm{X}_{x}, \mathrm{Y}_{y}, \mathrm{Z}_{z}, \mathrm{Y}_{z}, \mathrm{Z}_{x}, \mathrm{X}_{y}$ at the surface of the slab where there is discontinuity in the permeability $\mu$ and the forces per unit area are equal to the amounts of the discontinuities. Let the permeability of the slab be $\mu_{2}$, and let the permeability of the surrounding medium (air, in the present case) be $\mu_{1}$. The slab used is so thin that throughout its whole thickness the tubes of induction may be assumed parallel to the $\mathrm{X}$-axis, and consequently perpendicular to the faces perpendicular to the $\mathrm{X}$-axis.

With this assumption we have then

$$
\mathrm{Z}_{z}=\mathrm{Y}_{y}=\mathrm{Y}_{z}=\mathrm{Z}_{x}=\mathrm{X}_{y}=0,
$$

and $\iint \mathrm{X}_{x} d y d z$ taken over the two surfaces of the slab perpendicular to the $\mathrm{X}$-axis equals zero. In a similar way the surface-integral of the forces taken over the two surtaces perpendicular to the $\mathrm{Y}$-axis vanishes. But now consider the forces on the two faces perpendicular to the Z-axis. The conditions of symmetry applicable to the other faces do not hold here. Consider the lower $Z$-face, that is, the face between the poles. The equations show that all forces vanish at this face save $Z_{z}$, and we have then the force $Z_{z}$ given in medium of permeability $\mu_{1}$ by

$$
\mathrm{Z}_{z}=\frac{1}{8 \pi} \mathfrak{B}_{1} \mathrm{H}_{1},
$$

and in the slab or medium of permeability $\mu_{2}$ by

$$
\mathrm{Z}_{z}=\frac{1}{8 \pi} \mathfrak{B}_{2} \mathrm{H}_{2} \text {. }
$$


Diamagnetic and Weakly Magnetic Substances.

The difference in these two values gives us the total force acting upon the surface considered. If $\mathrm{P}_{1}$ denote its value in grams-weight, we have

$$
g \mathrm{P}_{1}=\frac{1}{8 \pi}\left\{\mathfrak{B}_{2} \mathrm{H}_{2}-\mathfrak{V}_{1} \mathrm{H}_{1}\right\} .
$$

But since $H$ near the surface is the same in both media, we have

$$
\begin{aligned}
g \mathrm{P}_{1} & =\frac{1}{8 \pi}\left(\mu_{2} \mathrm{H}_{1}{ }^{2}-\mu_{1} \mathrm{H}_{1}^{2}\right) . \\
& =\frac{\mu_{1} \kappa_{21} \mathrm{H}_{1}^{2}}{2} .
\end{aligned}
$$

Since $\kappa_{21}$ the relative susceptibility is by definition

$$
\kappa_{21}=\frac{1}{4 \pi}\left(\frac{\mu_{2}-\mu_{1}}{\mu_{1}}\right) \text {. }
$$

Now a similar trentment of the forces acting at the top surfice of the slab will give for the resultant force there

$$
g \mathrm{P}^{\prime}=\frac{\mu_{1} \kappa_{21} \mathrm{H}^{\prime 2}}{2}
$$

where $\mathrm{H}^{\prime}$ is the magnetic force at the top surface.

The difference between $P_{1}$ and $P^{\prime}$ times the area of the Z-face will give us the total force acting in the line of suspension. If $\mathrm{A}$ is the area of the $\mathrm{Z}$-face, then $\mathrm{P}$, the total vertical force, is given by

$$
\mathrm{P}=\frac{\kappa_{21} \mathrm{~A}}{2 g}\left(\mathrm{H}_{1}^{2}-\mathrm{H}^{\prime 2}\right) \text {. }
$$

Now experiment shows that $\mathrm{H}^{\prime 2}$ is negligible in comparison with $\mathrm{H}_{1}{ }^{2}$. If $\mu_{1}$, the permeability of air, be assumed equal to unity, we have

so that

$$
\mathrm{P}=\frac{\kappa}{2 g} \mathrm{AH}_{1}^{2}
$$

$$
\kappa=\frac{2 g \mathrm{P}}{\mathrm{A \textrm {H } ^ { 2 }}},
$$

where $\mathrm{H}$ is put for $\mathrm{H}_{1}$, and $\kappa$ for $\kappa_{21}$.

For the determination of $\kappa$ it is, accordingly, only necessary to determine $\mathrm{P}$ the mechanical force acting on the slab, $\dot{H}$ the magnetic force at the bottom of the slab, and the area of a cross-section of the slab. In determining the strength of the field the balance mentioned above was used. A known current is sent through a conductor placed in that part of the field the strength of which we wish to measure, and then the 
vertical force $F$ upon the conductor is determined by means of the balance. The field is given by the equation

$$
\mathrm{H}=\frac{10 g \mathrm{~F}}{l \mathrm{I}}
$$

where $I$ is the current in amperes, $l$ is the length of the wire in centimetres, $F$ is the force in grams measured by the balance.

A rectangular slab of plaster-of-paris was made with nearly the dimensions of the experimental slabs. On three edges of this slab (the bottom edge and the two side edges) were pasted thin strips of tinfoil just as wide as the slab was thick. Now when this slab is clamped in the clamp of the suspension apparatus, so that the tinfoil of the side edges is in contact with the metallic part of the surfaces $f$ and $f^{\prime}$, we shall have metallic connexion between $W$ and $W^{\prime}$ by way of the tinfoil along the sides and across the bottom of the slab. When a field determination is to be made the slab is adjusted with reference to the poles in just the same manner as are the experimental slabs. Then the tinfoil strip across the bottom of the slab is a conductor in the field we wish to determine. Since the corners turned by the tinfoil are very sharp the length of this conductor can be determined with great accuracy.

For the determination of the current I a Weston millivoltmeter was used in connexion with a german-silver shunt. The millivoltmeter was carefully calibrated by means of a Rayleigh current-weigher constructed by Mr. S. N. Taylor in connexion with his work on (lark and Westun cells.

\section{Method of Experimentation.}

The substance for a series of experiments having been selected, the field magnets were excited with the proper current regulated by a suitable resistance. An assistant kept the needle of an ammeter in circuit with the magnet coils always over a selected line of the scale. The plaster-of-paris slab described above was then introduced into the proper position. Equilibrium was obtained when no current passed through the conductor in the field and a reading of the balance taken. A current measured by the Weston millivoltmeter was then sent through the conductor and a new reading taken when equilibrium had been again secured. The difference in these two readings gave the force in grams $F$, due to the field, upon the current in the conductor. Then the plaster slab was removed and a slab of one of the substances to be investigated introduced, and a reading of the balance 
taken when equilibrium obtained. The slab was then reversed, top for bottom, and another reading obtained. This process was then gone through with all the five or six substances selected for a particular series of experiments, another determination of the field being made in the middle of the series and still another at the end.

After the last field determination, and while the field magnets were still excited, a reading of the balance was obtained with no slab in the clamp of the suspension apparatus. This reading was to enable us to make correction for any matgnetic action upon the suspension apparatus itself. The current through the magnet coils was then cut off.

The wires $w$ and $w^{\prime}$ were hung in long loops from fixed supports in the balance-case to a little rubber support firmly attached to the suspension rod P. From this, being well insulated, they were twined about the rod $P$ and connected with $\mathrm{W}$ and $\mathrm{W}^{\prime}$ at the nuts $d$ and $d^{\prime}$, as shown in fig. 4 . These wires would vary slightly in length when a current passed and correction hal to be made for this. Both wires $w$ and $w^{\prime}$ were connected with one nut (d, fig. 4) and the same current used in making the field determination was thus sent over the flexible wires in the balance-case, without going near the field magnets. A reading of the balance was taken when the current had been properly adjusted.

The residual field was then eliminated with great care. This was done by reversing over and over again a small current through the magnet coils until the balance gave no indication of a field when a current was sent through the conductor arranged as when the field was determined.

The slabs were then, each in turn, clamped in the clamp of the suspension apparatus and readings of the balance with the zero field taken. These readings, with those taken with the field on and with the proper corrections mentioned above, are sufficient to determine the mechanical force in the $Z$ direction. This force we have, in the theory of the method, called $P$.

A scale graduated to rend fifths of a millimetre was used to determine the width of the slab, and a Brown and Sharpe micrometer screw-gauge graduated to read thousandths of a centimetre was used to determine the thickness of the slab. The product of this width and thickness gave the area A. In making these width and thickness measurements, many measurements were taken on a given slab and the mean of these used in the calculations. 


\section{Results.}

The tabular results are, in general, arranged in groups which give the substances experimented upon and the data obtained in a given series of experiments.

A table of abbreviations, which will be found convenient in referring to the tables of data, is given below :-

H. Unit tubes of force per square centimetre at bottom surface of slab.

$p_{1}$. Balance reading in grams, tield on and slab in position.

$p_{0}$. Balance reading in grams, field off and slab in position.

$\boldsymbol{p}_{1}{ }^{\prime}$. Balance reading in grams, field on, plaster slab in position, and current through conductor.

$p_{0}{ }^{\prime}$. Balance reading in grams, field on, and plaster slab in position, but no current through conductor.

P. Mechanical force, in grams, upon the slab.

F. Mechanical force, in grams, upon conductor in field when current is on.

I. Current in amperes through conductor when field is being measured.

$\epsilon$. Correction necessary on account of magnetic attraction upon suspension apparatus without slab.

$\delta$. Correction necessary on account of extension in wires $w$ and $v v^{\prime}$ when current is sent through them.

$l$. Length, in centimetres, of conductor used in measuring field.

w. Mean width, in centimetres, of experimental slab.

$t$. Mean thickness, in centimetres, of experimental slab.

$\kappa$. Coefficient of magnetic susceptibility.

In the first series of experiments, determinations of $\kappa$ were made for five samples of marble. In the first column of the table are found the names of the different varieties of marble experimented upon. The second column gives $p_{1}$, two values being given for each substance, since each slab is reversed in each experiment, the top being put for the bottom; and the third column gives the mean of these two values. The fourth column gives $p_{0}$, the reading of the balance when slab is in position, but no field on. In the fifth column are the values of $\mathrm{P}=p_{0}-p_{1}+\epsilon$. In the next two columns are found $w$ and $t$, the factors of $A$, the area of the slab. The last column gives the values of $\kappa$ multiplied by 10 to the sixth power, which values are calculated from the data found in the columns and below. Below the columns are found the corrections $\epsilon$ and $\delta$, the necessary data for the calculation of $H$, and the calculated value of $H$. 'The same value of $H$ was used throughout a given series of experiments. The same arrangement of data and results is followed in all of the tables given. 
TABLE I.—Marble.

\begin{tabular}{|c|c|c|c|c|c|c|c|}
\hline & $p_{1}$. & $\begin{array}{c}\text { Mean } \\
p_{\mathrm{i}} .\end{array}$ & $p_{0}$ & $\begin{array}{c}\mathbf{P}= \\
p_{0}--p_{1}+\epsilon\end{array}$ & $w$ & $\ell$. & $\kappa \times 10^{5}$. \\
\hline Italian $\ldots \ldots\{$ & $\begin{array}{l}103 \cdot 3462 \\
103 \cdot 3463\end{array}$ & $103 \cdot 3462$ & $103 \cdot 4244$ & 0792 & $5 \cdot 18$ & $\cdot 490$ & -940 \\
\hline$\underset{\text { Statualy }}{\text { Italian }}\{$ & $\begin{array}{l}101 \cdot 2129 \\
101 \cdot 2146\end{array}$ & $101 \cdot 2138$ & $101 \cdot 2798$ & .0670 & $5 \cdot 13$ & 474 & -832 \\
\hline $\begin{array}{l}\text { Rutland } \\
\text { Stituary }\end{array}$ & $\begin{array}{l}102 \cdot 7416 \\
102 \cdot 7382\end{array}$ & 1027399 & $102 \cdot 8070$ & .0681 & 514 & .502 & -795 \\
\hline$\underset{\text { Grav }}{\text { Knoxrille }}$ & $\begin{array}{l}103 \cdot 7836 \\
103 \cdot 7832\end{array}$ & $103 \cdot 7834$ & 1038336 & .0512 & $5 \cdot 12$ & 500 & -603 \\
\hline$\underset{\text { Statuars (2) }}{\text { Ttalian }}\{$ & $\begin{array}{l}102 \cdot 8600 \\
102 \cdot 86 \geq 0\end{array}$ & $102 \cdot 8610$ & 102.9279 & .0679 & $5 \cdot 14$ & $\cdot 491$ & -811 \\
\hline & $\begin{array}{c}p_{1}^{\prime} \\
746630\end{array}$ & $\begin{aligned} & p_{0} \dot{ } \\
& 73 \cdot 072 \\
& \mathbf{\epsilon}==0010 \\
& \delta= 0027\end{aligned}$ & & $\begin{array}{c}\mathbf{F}= \\
-p_{0}+\delta . \\
1.593 \\
l=4.54 \\
I=-427\end{array}$ & $\underset{8,060}{\text { H. }}$ & & \\
\hline
\end{tabular}

Special attention was thus bestowed upon the study of the magnetic properties of marble since it has been often used as a means of support for cuils in standard apparatus. The results obtained seem to indicate that almost any variety of marble can be relied upon to he diamagnetic and free from iron, and to have a magnetic susceptibility of about $-\cdot 8 \times 10^{-6}$. Therefore it would seem that a free use of marble in magnetic apparatus is allowable.

Table II. gives the data and results for aluminium, glass, and tin.

TABLE II.

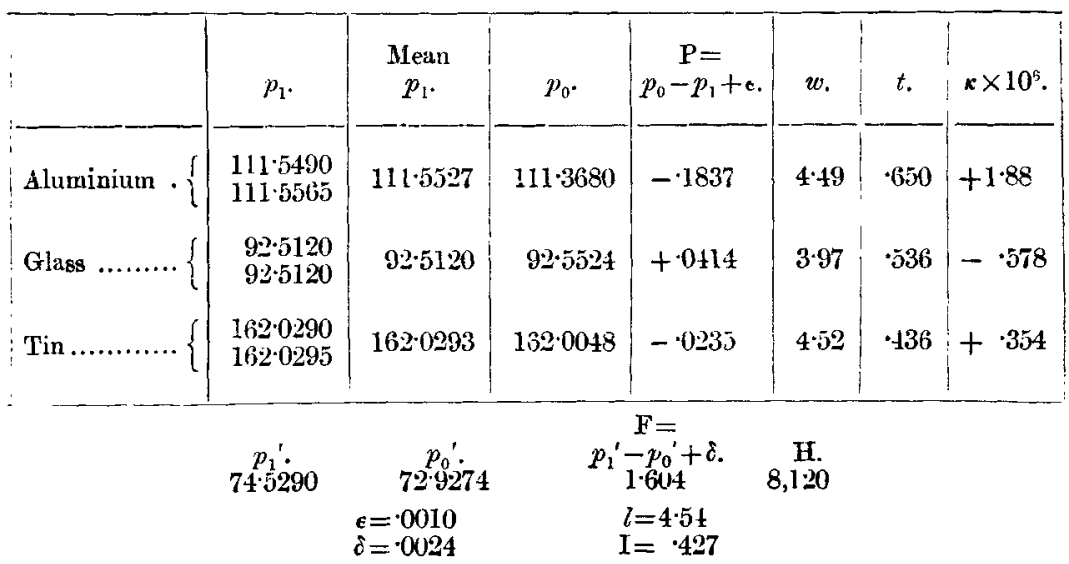


444 Mr. A. P. Wills on the Susceptibility of

It should be noticed that the coefficient of susceptibility for tin is positive, that is, the present experiments would seem to indicate that tin is magnetic. Now previous experiments upon tin have clearly shown it to be diamagnetic, and the conclusion to be drawn in the present case is that the sample used must have contained traces of iron. The glass used was a piece of fine optical glass. The value of $\kappa$ obtained for this piece of glass is four or five times the value usually given. Aluminium is seen to have a positive value of $\kappa$ and quite large.

TABLE III.

\begin{tabular}{|c|c|c|c|c|c|c|c|}
\hline & $p_{1}$ & $\begin{array}{c}\text { Mean } \\
p_{1} .\end{array}$ & $p_{0}$ & $\begin{array}{c}\mathbf{P}= \\
p_{0}-p_{2}+\epsilon\end{array}$ & $w$ & $t$. & $x \times 10^{8}$. \\
\hline Antimong $\ldots\{$ & $\begin{array}{l}17333254 \\
173 \cdot 3320\end{array}$ & 1733287 & $173 \cdot 3830$ & .0553 & 4.55 & $\cdot 495$ & $-\quad 714$ \\
\hline Bismuth...... & $\begin{array}{l}202 \cdot 5290 \\
202: 5970\end{array}$ & $202 \cdot 5630$ & $203 \cdot 3932$ & .8312 & $4: 58$ & $\cdot 430$ & $-12 \cdot 25$ \\
\hline Sulpbur ...... & $\begin{array}{l}96 \cdot 3017 \\
96 \cdot 2963\end{array}$ & $96 \cdot 2990$ & $96 \cdot 3817$ & $\cdot 0837$ & $4 \cdot 94$ & $\cdot 644$ & -765 \\
\hline Ebonite ...... & $\begin{array}{l}80 \cdot 9105 \\
80 \cdot 9232\end{array}$ & 80.9168 & $80 \cdot 7964$ & $-\cdot 1194$ & 4.94 & 648 & +1.08 \\
\hline Paraffin ...... & $\begin{array}{l}64 \cdot 4940 \\
64 \cdot 5054\end{array}$ & $64 \cdot 4997$ & $64: 5480$ & $\cdot 0+93$ & $4 \cdot 44$ & .559 & $-\quad .57 t$ \\
\hline White Wax $\cdot\{$ & $\begin{array}{l}63 \cdot 7308 \\
63 \cdot 7298\end{array}$ & 63.7303 & $63 \cdot 7811$ & 0518 & 4.94 & .544 & $-\quad 560$ \\
\hline Shellac & $\begin{array}{l}74 \cdot 1848 \\
74 \cdot 2178\end{array}$ & $74 \cdot 2013$ & $74 \cdot 2422$ & 0419 & 5.03 & $\cdot 615$ & - 394 \\
\hline
\end{tabular}

$\begin{array}{cccc}p_{1}{ }^{\prime} & & \mathrm{F}= & \\ 74 \cdot 6347 & p_{0}{ }^{\prime} & p_{\mathrm{l}}^{\prime}-p_{0}^{\prime}+\delta . & \mathrm{H} . \\ & 73 \cdot 0140 & 1 \cdot 623 & 6,740 \\ & \epsilon=\cdot 0010 & l=4 \cdot 54 & \\ & \delta=\cdot 0026 & \mathrm{I}=\cdot 427 & \end{array}$

The bismuth used in this series was furnished by Eimer and Amend, of New York, and was supposed to be chemically pure. The results for antimony seem to show that the sample used must have contained just a trace of iron, since the value found for $\kappa$, while negative, is much smaller than that usually given.

Table IV. gives the results found for several kinds of wood. 
TABLE IV.

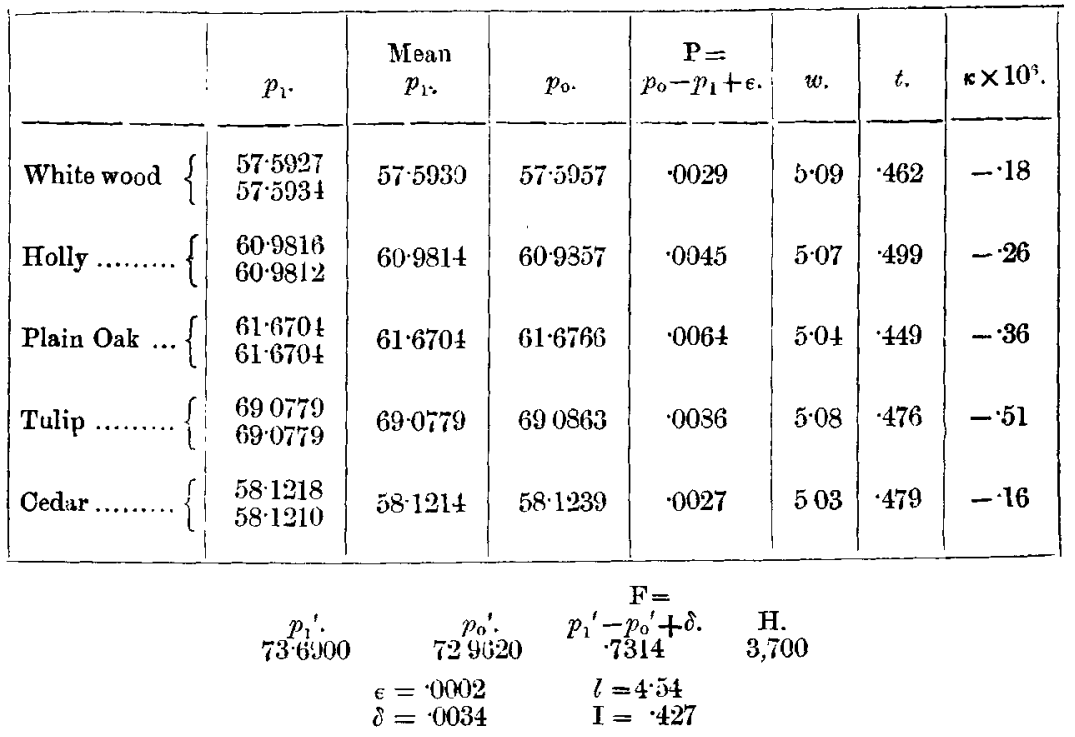

These results show, in general, that the grenter the density of the wood the greater is the coefficient of magnetic susceptibility.

Besides these quantitative experiments there were made a large number of qualitative experiments upon a great many different kinds of wood. Only one kind out of abont twenty different kinds tried proved to be magnetic, the rest were diamagnetic ; the exception was butternut.

There has been in the past a difference of opinion among physicists as to whether diamagnetic substinces are or are not less susceptible under the application of large magnetizing forces. Most of the earlier experimenters, among them Tyndall, Joule, and Becquerel, found reason to believe that $x$ is constant for diamagnetic substances. Plücker, however, believed that in some cases, as the magnetizing force is increased the coefficient of susceptibility $\kappa$ for diamagnetic bodies decreases in a similar way as in iron. Plücker also thought he observed in some cases an increase in $\kappa$ with an increase in the magnetizing force up to a certain point, after that a decrease; that is, for a certain value of the magnetizing force $\kappa$ has a maximum. Silow* (1880) published results which indicate that $\kappa$ for ferric chloride increases for a while

* Wied. Ann, ii. p. 324 (1880).

Phil. Mag. S. 5. Vol. 45. No. 276. May 1898. $2 \mathrm{H}$ 
with the magnetizing force, reaches a maximum, and decreases.

The fifth series of experiments was undertaken in the hope of showing definitely whether. bismuth, the strongest diamagnetic substance known, does or does not vary in its susceptibility to magnetization as the magnetizing force is made to vary.

Table V., which gives the results of experiments upon bismuth using widely different fields, is arranged in a way similar in all respocts to the preceding tables.

'Table V.-Bismuth.

\begin{tabular}{|c|c|c|c|c|c|c|c|}
\hline & $p_{1}$ & $\begin{array}{c}\text { Mean } \\
p_{1} .\end{array}$ & $p_{0}$ & $\begin{array}{c}\mathbf{P}= \\
p_{0}-p_{1}+\varepsilon .\end{array}$ & $w$ & $t$. & $\kappa \times 10^{5}$. \\
\hline Bismuth (1) \{ & $\begin{array}{l}203 \cdot 0078 \\
203 \cdot 0090\end{array}$ & 2030084 & 2030114 & .0330 & $4: 58$ & -430 & $-12 \cdot 55$ \\
\hline Bismuth (2) \{ & $\begin{array}{l}202 \cdot 8664 \\
202 \cdot 8810\end{array}$ & $202 \cdot 8737$ & $203 \cdot 0400$ & $\cdot 1663$ & $"$ & , & $-12 \cdot 25$ \\
\hline Bismuth (3) \{ & $\begin{array}{l}202 \cdot 5290 \\
202 \cdot 5970\end{array}$ & $202 \cdot 5630$ & $203 \cdot 3932$ & .8302 & " & ", & $-12 \cdot 25$ \\
\hline Bismuth (4) \{ & $\begin{array}{l}202 \cdot 0909 \\
202 \cdot 1010\end{array}$ & $202 \cdot 0959$ & 2030400 & 9141 & ", & " & $-125 \tilde{j}$ \\
\hline Bismuth (5) \{ & $\begin{array}{l}201 \cdot 6156 \\
201 \cdot 7310\end{array}$ & $201 \cdot 6733$ & 2030400 & 1.367 & " & " & $-12 \cdot 45$ \\
\hline \multicolumn{8}{|c|}{$\begin{array}{ll}\text { (1) } & 72 \cdot 96 \\
\text { (2) } & 73 \cdot 36 \\
\text { (3) } & 74 \cdot 6 \\
\text { (4) } & 74 \cdot 27 \\
\text { (5) } & 74 \cdot 55\end{array}$} \\
\hline
\end{tabular}

Note. -The current used in making the field determinations was in all cases, except the third, -398 ampere; in the third case it was 427 ampere. $l=4 \cdot 54$. $\delta$ was approximately equal in all cases to 0020 . E was negligible.

As the table shows, the fields used in the last series of experiments vary between the limits of 1,620 and 10,450 lines per square centimetre. The results show that within these wide limits $\boldsymbol{\kappa}$ is constant for bismuth.

A similar series of experiments upon white wax indicated that $\boldsymbol{\kappa}$ for this substance is constant within wide limits of the field-strengths; and in the light of these results it would seem probable that for solids, at any rate, $\kappa$ is constant.

The method for the study of magnetic and diamagnetic 
phenomena in solid bodies, described in the present papar, is easily adapted to the study of liquids, and of gasos under different pressures.

At various intervals during the present century many different physicists have been interested in the study of diamagnetism. But notwithstanding the fact that many have worked upon the problems which a study of diamagnetism offers, there seem to be some things in connexion with the subject which merit more careful investigation. For instance, the question as to whether or not a diamagnetic body, after being under the influence of a magnetizing force and this force withdrawn, requires, if left mechanically undisturbed, a "coercive force" to bring it to the neutral magnetic state again, is still an open one. Of course the extreme smallness of the action to be measured is the great difficulty encountered in any quantitative work in diamagnetism.

For the illustrations used in this paper I have to thank Mr. Joseph Daniels, of the Colorado State Normal School. I am under great obligations to Dr. A. G. Webster, Protessor of Physics at Clark University, for suggestions and advice given while the work was being carried out, also to Clark University for providing the necessary apparatus.

XLV. On the Function of the Condenser in an Induction-Coil. By T. Mrzuxo, Rigakushi* *

TTHE efficiency of an induction-coil is greatly increased by the employment of a condenser in its primary circuit, in accordance with Fizeau's suggestion, but the part played by the condenser is not yet clearly known. The most commonly accepted opinion is that the extra current in the primary circuit, instead of being expended in making a spark at the interruptor, darts into the condenser and hastens the decay of the primary current, therehy raising the terminal potentialdifference of the secondary circuit. Moreover, according to this view, if a condenser is inserted across the interruptor, then on breaking the primary current it continues to run on into the condenser for a while; but then rebounds, and is reversed in sign, retaining its initial full strength. Hence the electromotive force set up in the secondary circuit is the joint result of a stoppage of a primary current and its immediate reversal in direction. But this simple explanation, however plausible at first sight, is yet an imperfect account of the function of the condenser. In this paper, I propose to

* Communicated by the Author.

$2 \mathrm{H} 2$ 